Article

\title{
Powertrain Optimization for Electric Buses under Optimal Energy-Efficient Driving
}

\author{
Alexander Koch ${ }^{1, *(\mathbb{D}}$, Olaf Teichert ${ }^{2} \mathbb{D}$, Svenja Kalt $\left.{ }^{1} \mathbb{(}\right)$, Aybike Ongel ${ }^{2}(\mathbb{D}$ and \\ Markus Lienkamp ${ }^{1,2}$ \\ 1 Institute of Automotive Technology, Technical University of Munich, 85748 Garching, Germany; \\ kalt@ftm.mw.tum.de (S.K.); lienkamp@ftm.mw.tum.de (M.L.) \\ 2 TUMCREATE Ltd., Singapore 138602, Singapore; olaf.teichert@tum-create.edu.sg (O.T.); \\ aybike.ongel@tum-create.edu.sg (A.O.) \\ * Correspondence: koch@ftm.mw.tum.de
}

Received: 3 November 2020; Accepted: 29 November 2020; Published: 6 December 2020

\begin{abstract}
State of the art powertrain optimization compares the energy consumption of different powertrain configurations based on simulations with fixed driving cycles. However, this approach might not be applicable to future vehicles, since speed advisory systems and automated driving functions offer the potential to adapt the speed profile to minimize energy consumption. This study aims to investigate the potential of powertrain optimization with respect to energy consumption under optimal energy-efficient driving for electric buses. The optimal powertrain configurations of the buses under energy-efficient driving and their respective energy consumptions are obtained using powertrain-specific optimized driving cycles and compared with those of human-driven unconnected buses and buses with non-powertrain-specific optimal speed profiles. Based on the results, new trends in the powertrain design of vehicles under energy-efficient driving are derived. The optimized driving cycles are calculated using a dynamic programming approach. The evaluations were based on the fact that the buses under energy-efficient driving operate in dedicated lanes with vehicle-to-infrastructure (V2I) communication while the unconnected buses operate in mixed traffic. The results indicate that deviating from the optimal powertrain configuration does not have a significant effect on energy consumption for optimized speed profiles; however, the energy savings from an optimized powertrain configuration can be significant when ride comfort is considered. The connected buses under energy-efficient driving operating in dedicated lanes may reduce energy consumption by up to $27 \%$ compared to human-driven unconnected buses.
\end{abstract}

Keywords: energy-efficient driving; eco-driving; speed profile optimization; powertrain optimization; dynamic programming

\section{Introduction}

Current road-based transport systems are dominated by combustion vehicles, which have a major impact on energy consumption, air pollution and greenhouse gas emissions. In Singapore, transportation is responsible for $17.6 \%$ of the total energy consumption, of which around $90 \%$ is obtained from petroleum products [1]. Though $15 \%$ of all transportation carbon emissions in Singapore are produced by buses [2], they make up only $2 \%$ of all vehicles on the road [3]. This means that even small improvements in the energy efficiency of buses may have a significant impact on overall emissions. Technological improvements in the field of alternative power sources, driving assistance and intelligent control have the potential to reshape the environmental profile of the current transportation systems. 
Energy consumption can be reduced at the operational level as well as at the vehicle level. By reducing drag and using an efficient powertrain, energy consumption can be minimized at the vehicle level. The operation level describes the usage of the vehicle and the driving style, which also has an influence on power demand.

Sciarretta [4] (p. 142) gives a summary of energy-efficient driving and names dynamic programming (DP) and Pontrayagin's maximum principle (PMP) as the most used numerical techniques to solve these problems. Han et al. [5] differentiates between the minimization of the "wheel to distance" energy, which does not consider the powertrain, and the minimization of "tank to distance" energy, which does. It was shown for the "wheel to distance" optimization that the optimal speed profile between two stops consists of maximal acceleration, cruising and, depending on the regeneration ability, coasting and/or maximal breaking. Furthermore, considering a combustion powertrain, repeated accelerating and coasting, also called a pulse and glide (P\&G) strategy, can be more efficient than cruising, as the load points of the motor are shifted toward better efficiency. Eo et al. [6] demonstrated the pulse and glide strategy for a hybrid vehicle on a dynamometer. So et al. [7] showed that $P \& G$ may also reduce energy consumption for battery electric vehicles (BEVs). Lajunen [8] investigated optimized speed profiles for different powertrain types using a DP algorithm. Taking the load-point-dependent efficiency of the powertrain into account, the optimized speed profile reduced the required energy consumption by $12 \%$ for the electric and $13 \%$ for the diesel powertrain compared to the reference driving cycle for the considered bus. Kelouwani et al. [9] lists energy savings between $14 \%$ and $21 \%$ compared to human drivers by using DP to optimize the speed profile. However, no motor efficiency map was used in this study. Mensing et al. [10] achieved 19\% energy savings by optimizing the New European Driving Cycle (NEDC) for a small vehicle with a combustion engine. References [11,12] presented a DP approach for a driver assistance system to optimize fuel consumption. Luu et al. [11] used different cost coefficients for arrival time, fuel consumption and comfort and showed that optimizing the fuel consumption results in longer travel times and can result in uncomfortable speed profiles due to oscillation, which equates to the P\&G strategy. Additionally, vehicle-to-infrastructure (V2I) communication may allow for further energy savings by supporting vehicles in avoiding unnecessary acceleration or deceleration when approaching traffic signals through traffic actuated signals [13], green light optimized speed advisory [14] or a combination of both [15]. Teichert et al. [16] compared different combinations of eco-driving strategies and traffic management measures. Results show that a dedicated lane with traffic light information results in the highest energy savings, while the savings in mixed traffic depend on the maximal allowed inter-vehicle distance. These strategies can be implemented as driver assistance for human-driven vehicles [11,12,14]. Furthermore, the automatization of vehicles is seen as an enabler of energy-efficient driving since optimal speed profiles are no longer an advisory for a human driver but can be implemented through a control strategy [4] (p. 8).

BEVs offer another opportunity to reduce energy consumption $[17,18]$. Nonetheless, the adoption of electric vehicles has been slow, due to the small vehicle range, which is mainly caused by limitations in battery technology [19]. Apart from improving battery technology, the effective range of an electric vehicle can be increased by reducing its energy consumption. Powertrain concept optimization is a method to reduce the energy consumption of a future vehicle and can be conducted at different abstraction levels of the vehicle: sizing the components, choosing the components and designing the powertrain topology [20].

Improving energy efficiency at the component size and type level includes the optimization of the motor and gearbox combination [21-23]. Regarding the motor type, the permanent magnet synchronous machine (PMSM) and induction machine (IM) are the most commonly used alternatives in electric vehicles on the market [24,25]. The advantages and disadvantages of both types have been studied extensively [26-30]. In general, PMSMs have a better power density and overall efficiency, whereas IMs are the less expensive option [26]. Furthermore, the two motor types reach optimal efficiencies at different speed-torque load points. References [27-29] conducted a direct comparison 
between a PMSM and IM for a battery electric hybrid vehicle, concluding that the energy losses in the IM were higher for the considered UDDS, HWFET and US06 driving cycles. Pellegrino et al. [30] performed a detailed comparison in terms of output power and efficiency among a surface-mounted PMSM, an interior PMSM and an IM. The energy consumption analysis revealed that the interior PMSM performed best, followed by the IM and then the surface-mounted PMSM for the regarded NEDC.

Another aspect of the powertrain configuration is the transmission design. With a fixed driving cycle, the gear ratio defines the load points of the motor and, thus, the optimal gear ratio matches the frequent load points of the driving cycle to the high-efficiency regions of the motor [31]. Wang et al. [31] investigated different powertrain topologies using a genetic algorithm solver, optimizing the motor size and gearbox ratio to achieve the lowest energy consumption for a given driving cycle. Hofman et al. [22] compared the energy efficiency of different motor and gear ratio combinations for an ultra-light vehicle with a single speed gearbox based on two driving cycles. The results showed the high dependency of the energy consumption on the gear ratio.

Some studies incorporated energy-efficient driving in powertrain optimization. Tate et al. [32] investigated the efficiency gains due to connected autonomous driving, mainly through the example of a combustion vehicle. Speed profiles were smoothed and the engine was downsized. References $[33,34]$ optimized the powertrain and speed profile of an automated/autonomous BEV, using DP to generate speed profiles. Anselma and Belingardi [33] assumed optimal cooperative driving. Thus, it was assumed that the vehicle knows the entire speed profile of the leading vehicle a priori. The results indicate that the optimal powertrain configurations of a human-driven vehicle and a connected autonomous vehicle under optimal control differ. Gambhira [34] used driving cycles as a reference and assumed no traffic. He concluded that savings are higher due to optimal driving rather than due to powertrain optimization. However, no study incorporated traffic lights and V2I communication in their optimization. Furthermore, these studies do not explain the differences in the powertrain design of vehicles derived from driving cycles and vehicles under energy-efficient driving.

Most studies investigating the impact of powertrain configuration on energy consumption in the literature rely on driving cycles. The emergence of connected driving assistance systems and connected automated driving systems has brought unprecedented opportunities to further improve the energy usage through predictive control strategies. While there is abundant literature showing the substantial energy consumption improvement benefits achieved through optimized speed profiles, the simultaneous optimization of speed profile and powertrain configuration using V2I communication has never been conducted. This study aims to investigate the potential of powertrain optimization with respect to energy consumption under optimal speed control. Furthermore, the effects of optimal powertrain configuration for connected, energy-efficient driven buses (CEEDBs) with fixed driving cycles and human-driven unconnected buses without speed advisory (UCBs) are analyzed. Based on the results, new trends in the powertrain design of connected vehicles under energy-efficient driving are derived. The optimization uses an enumerative approach in which the speed profile of each powertrain configuration is optimized for minimum energy consumption using DP, taking the traffic light and speed constraints into account. The speed profile optimization assumes that the connected energy-efficient driven bus (CEEDB) is operated in dedicated lanes with V2I communication. The energy consumption of the human-driven unconnected bus (UCB) is based on the measured speed profiles of two buses operating on two different bus routes in Singapore. 


\section{Methodology}

\subsection{Vehicle Speed Optimization}

The speed profile of the BEV is optimized for minimum energy consumption using a DP algorithm [35]. The problem is formulated as:

$$
\min _{T_{k}} \sum_{k=0}^{N-1} E\left(x_{k}, T_{k}\right) \quad \text { where } \quad\left\{\begin{array}{l}
x_{k+1}=f\left(x_{k}, T_{k}\right) \\
x_{k} \in\left[x_{k, \min } x_{k, \max }\right] \\
T_{k} \in\left[T_{k, \min } T_{k, \max }\right]
\end{array}\right.
$$

where $x_{k}$ is the system state, which consists of the vehicle speed and time from the starting point; $T_{k}$ is the control input, which corresponds to the traction torque at the wheel; and the subscript $k$ represents the discrete distance from the starting point. The problem is defined in the spatial domain, since the boundary conditions along the route, such as traffic lights and speed limits, are distance-based characteristics. The solution of the problem finds the torque control strategy that minimizes the total consumed energy $E$, while considering the boundary conditions for the state and control variables.

The calculation of the energy consumption is based on a longitudinal vehicle simulation. First, the traction torque is discretized between two torque limits. The discretization at the traction torque level was used to achieve the same discretization for different gear ratios. Subsequently, for all torques, the resulting vehicle acceleration is calculated using Equation (2).

$$
a_{k}=\frac{1}{m}\left(\frac{T_{k}}{r_{\text {tire }}}-F_{\text {drag }}-F_{\text {roll }}-F_{\text {slope }}\right)
$$

where $a_{k}$ corresponds to the acceleration, $r_{\text {tire }}$ is the tire radius, $m$ is the vehicle weight and $F_{\mathrm{drag}}$, $F_{\text {roll }}$ and $F_{\text {slope }}$ correspond to the vehicle drag, roll and slope resistance, respectively. The resistance forces are calculated based on the equations given in [36] with constant drag coefficients.

Based on the derived acceleration, the new state variables are calculated with Equations (3) and (4), where $v$ corresponds to the vehicle speed, $s$ is the distance from the start and $t$ is the time from the starting point.

$$
\begin{gathered}
v_{k+1}=\sqrt{v_{k}^{2}+2\left(s_{k+1}-s_{k}\right) a_{k}} \\
t_{k+1}=t_{k}+\frac{2\left(s_{k+1}-s_{k}\right)}{v_{k+1}+v_{k}}
\end{gathered}
$$

The motor torque $T_{\mathrm{M}}$ and motor speed $n$ are calculated based on the gear ratio $i$ and its efficiency $\eta_{\mathrm{G}}$ by Equations (5) and (6). Even though the efficiency of a gearbox is dependent on speed and torque, an assumption of a constant efficiency is reasonable [37].

$$
\begin{gathered}
T_{\mathrm{M}, k}= \begin{cases}\frac{T_{k}}{i \eta_{\mathrm{G}}}, & \text { Traction } \\
\frac{T_{k} \eta_{\mathrm{G}}}{i}, & \text { Recuperation }\end{cases} \\
n_{k}=\frac{1}{r_{\text {tire }}} \frac{v_{k+1}+v_{k}}{2} i
\end{gathered}
$$

Finally, the energy consumption to move to the next state is calculated using Equation (7):

$$
E_{k}= \begin{cases}\left(T_{\mathrm{M}, \mathrm{k}} \frac{1}{\eta_{k}} n_{k}\right)\left(t_{k+1}-t_{k}\right), & \text { Traction } \\ \left(T_{\mathrm{M}, \mathrm{k}} \eta_{k} n_{k}\right)\left(t_{k+1}-t_{k}\right), & \text { Recuperation }\end{cases}
$$

where $\eta$ is the motor efficiency derived from the motor map for the current load point. 
The optimal control strategy for the traction torque can then be found by implementing an optimal path search, which is evaluated backwards at discrete distances $s_{k}$. The algorithm is implemented in MATLAB in a vectorized form to improve computation time. Its main sequence is similar to [38].

\subsection{Ride Comfort Evaluation}

Since lack of comfort is not penalized, the optimization algorithm may lead to uncomfortable speed profiles due to $P \& G$. The optimal controlled vehicle may oscillate around a certain speed, which may result in a jagged speed profile. Ref. [11] showed this effect for light vehicles with combustion engines and smoothed the speed profile with an added term in the cost function. To gain more comfortable and thereby realistic speed profiles and determine the effects of comfort on the powertrain configuration and energy consumption, further optimizations are conducted with a modified cost function (Equation (8)). With the weighted sum method [39], multiple objectives can be reduced to one scalar value. Similar to [11], who used weighted penalty for acceleration, the new cost function, given in Equation (9), penalizes jerk, whereas $j$ represents the jerk.

$$
\begin{gathered}
\min _{T_{k}} \sum_{k=0}^{N-1} C\left(x_{k}, T_{k}\right) \quad \text { where }\left\{\begin{array}{l}
x_{k+1}=f\left(x_{k}, T_{k}\right) \\
x_{k} \in\left[x_{k, \min } x_{k, \max }\right] \\
T_{k} \in\left[T_{k, \min } T_{k, \max }\right]
\end{array}\right. \\
C=E+c_{1} j^{6}+ \begin{cases}0 & \operatorname{abs}(j)<1 \\
c_{2} & \operatorname{abs}(j) \geq 1\end{cases}
\end{gathered}
$$

The weights and exponents of the cost function have been selected based on iterative simulations of speed profiles for all motor types and gear ratios to reduce $P \& G$ while leaving enough freedom to save energy due to gliding. The first term minimizes the jerk in general. The last term penalizes the jerk values over 1 . Values were set to $c_{1}=9 \cdot 10^{6}$ and $c_{2}=10^{10}$. Other similar approaches using the weighted sum method can be seen in [40,41]. To find the global optimal solution, the DP algorithm would require acceleration as an additional state. As this would increase the computation time to a great extent, another approach was chosen. The acceleration of the optimal control at $s_{k}$ is saved. At $s_{k-1}$, the control vector is applied for all discrete points and the jerk is calculated by Equation (10).

$$
j_{k}=\frac{a_{k+1}-a_{k}}{t_{k+1}-t_{k}}
$$

\subsection{Derivation of Boundary Conditions and Discretization}

To find the optimal control strategy for the motor torque and the corresponding speed profile for a given route, the boundary conditions along the route need to be taken into account, i.e., speed limits, permitted cornering speed, traffic lights, stops and the total available time to complete the route.

The speed of the vehicle on straight segments of the road is capped at speed limits, while the maximum speed at the turns is calculated using Equation (11), with $a_{\text {lat,max }}$ describing the upper bound of comfortable lateral acceleration and $r_{\text {corner }}$ the cornering radius. Additionally, longitudinal acceleration is limited to $1 \mathrm{~m} / \mathrm{s}^{2}$ to ensure comfort. As an example, the resulting speed boundary profile is shown for a $3000 \mathrm{~m}$ stretch of a bus route with eight stops and eight turns in Figure 1a.

$$
v_{\text {corner }}=\sqrt{a_{\text {lat,max }} r_{\text {corner }}}
$$

The lower and upper time bounds are calculated by Equations (12) and (13), respectively, where $t_{k, \text { min }}$ is the lower time bound, $t_{k, \max }$ is the upper time bound, $v_{k, \max }$ refers to the upper speed bound based on the acceleration limit, $t_{\mathrm{end}}$ is the maximum time to complete the route and $t_{\mathrm{dwell}}$ is the dwelling time at the stops. The maximum time to complete the route and the dwelling time are based on actual bus operation data. Subsequently, the effect of traffic lights on the obtained upper and 
lower time bounds is incorporated. Traffic lights are modeled by a red phase and a green phase, where the duration of the green and red phases is fixed. When a red phase is encountered, the lower time bound is shifted up, while the upper time bound is shifted down. An example of the resulting upper and lower time bounds is shown in Figure $1 \mathrm{~b}$.

$$
\begin{gathered}
t_{k, \min }=\sum_{i=1}^{k} \frac{2\left(s_{i}-s_{i-1}\right)}{v_{k, \max }+v_{k-1, \max }} \\
t_{k, \max }=t_{k, \min }+t_{\mathrm{end}}-t_{\mathrm{dwell}}-t_{N, \min }
\end{gathered}
$$

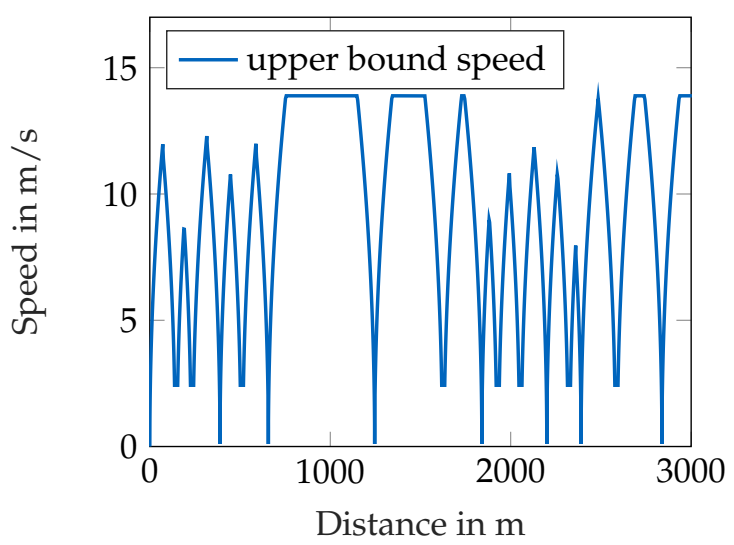

(a)

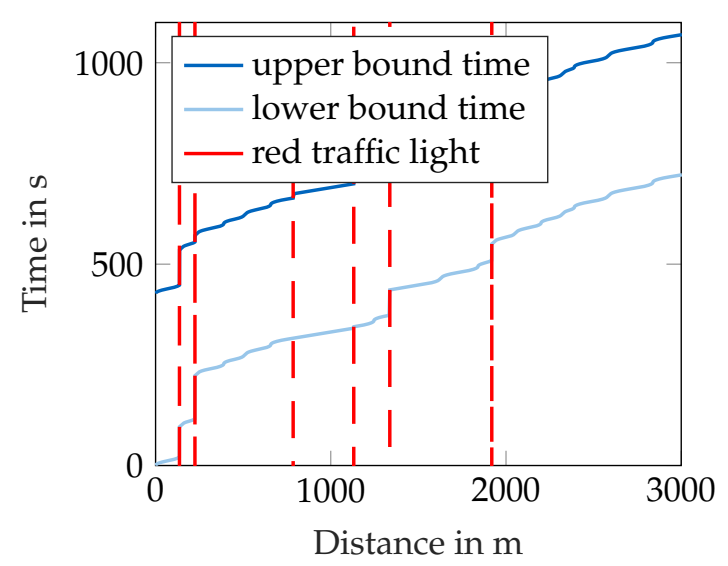

(b)

Figure 1. Example of the solution space for (a) speed and (b) time.

The optimization is conducted along distance s. The step size in s varies, depending on the upper bound of the speed. Thereby, the discretization is small where the vehicle is expected to be slow and wider where the vehicle is expected to be faster. The step size in s was set such that, corresponding to the upper bound speed, delta $\mathrm{t}$ is $0.3 \mathrm{~s}$ but not smaller than $0.2 \mathrm{~m}$. The speed was discretized with 300 equally spaced points between the upper limit and zero. A stop was approximated with an upper value of $0.1 \mathrm{~m} / \mathrm{s}$. Time was discretized between the lower and upper bound with 350 equally distanced points and traction torque at the wheel was discretized in $15 \mathrm{Nm}$ steps.

\subsection{Assumptions}

Various assumptions were made in the speed profile optimization. To see the effect of energy-efficient driving on the powertrain, it was assumed that the vehicle follows the optimal speed profile at all times, representing a best case scenario. With the V2I communication, the signal phase timings of all traffic lights are available before the start of the journey. Additionally, since the CEEDB drives in a dedicated lane, it was assumed that there are no vehicles or pedestrians that interfere with the bus operation. To see the effects of the powertrain isolated, the auxiliary power was set to zero.

\section{Case Study}

The powertrain optimization was implemented for the two bus routes in Singapore, routes 91 and 185, as they differ in their characteristics and represent two types of bus routes. Route 91 connects an MRT station to a business park and is characterized by frequent turns and a relatively short distance between stops. Route 185 connects a residential area to an industrial area via an expressway. The expressway section has a length of $4.2 \mathrm{~km}$, with no stops or traffic lights, and a speed limit of $60 \mathrm{~km} / \mathrm{h}$ instead of the standard $50 \mathrm{~km} / \mathrm{h}$ speed limit. Route 185 is therefore characterized by 
longer straight segments and a higher average speed than Route 91. Measurement data in the form of geographic coordinates and speed were recorded for each route using a smartphone app [42]. Wittmann et al. [42] proposes the use of these data for the determination of energy consumption. Since the buses on Route 91 operate in a loop, the full operation was recorded, while for Route 185 , which is bidirectional, only operation in the east-west direction was recorded. The obtained information was combined with the geographic location data of traffic lights and bus stops provided by the Singapore Land Transport Authority [43]. Figure 2 shows the measured route and the locations of stops and traffic lights. The measured route length, number of stops, average distance between stops, number of turns, number of traffic lights, speed limits, duration, total dwelling time and average speed of both routes are summarized in Table 1.

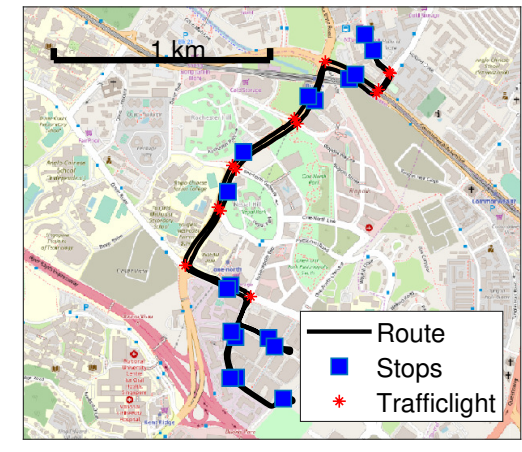

(a)

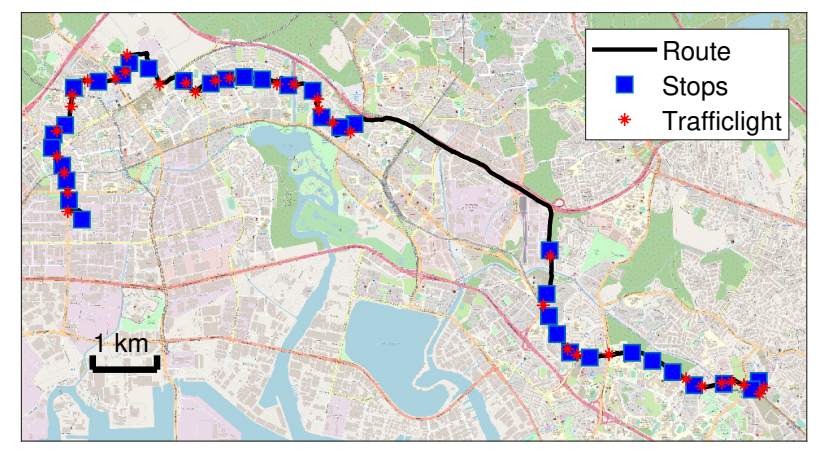

(b)

Figure 2. Map showing the path, stops and traffic lights of (a) Route 91 and (b) Route 185.

Table 1. Bus route characteristics.

\begin{tabular}{lcc}
\hline Parameter & Bus Route 91 & Bus Route 185 \\
\hline Measured route length & $6.0 \mathrm{~km}$ & $15.9 \mathrm{~km}$ \\
Measured number of bus stops & 13 & 28 \\
Average distance between stops & $460 \mathrm{~m}$ & $570 \mathrm{~m}$ \\
Number of turns & 14 & 14 \\
Number of traffic lights & 18 & 45 \\
Speed limits & $50 \mathrm{~km} / \mathrm{h}$ & 50 or $60 \mathrm{~km} / \mathrm{h}$ \\
Duration & $1612 \mathrm{~s}$ & $3766 \mathrm{~s}$ \\
Dwelling time & $114 \mathrm{~s}$ & $565 \mathrm{~s}$ \\
Average speed (without dwelling) & $14.4 \mathrm{~km} / \mathrm{h}$ & $17.9 \mathrm{~km} / \mathrm{h}$ \\
\hline
\end{tabular}

The longitudinal vehicle simulation was based on the vehicle characteristics of the $12 \mathrm{~m}$ battery electric BYD bus [44], hereinafter referred to as the reference vehicle. The mass, front area, drag coefficient, rolling resistance coefficient, tire radius and transmission efficiency are listed in Table 2. The bus is powered by a pair of motors connected to the rear drive axle, with a single gear stage at each wheel (see Figure A1). The torque is assumed to be split evenly between both motors. For the CEEDB and UCB, the same vehicle model and energy consumption simulation is used to see the effect of energy-efficient driving on powertrain design. 
Table 2. Reference vehicle parameters.

\begin{tabular}{lcc}
\hline Parameter & Value & Source \\
\hline Mass & $15,850 \mathrm{~kg}$ & {$[44]$} \\
Front area & $8.6 \mathrm{~m}^{2}$ & {$[44]$} \\
Drag coefficient & 0.7 & assumption \\
Rolling resistance coeff. & 0.008 & {$[45]$} \\
Tire radius & $0.48 \mathrm{~m}$ & {$[44]$} \\
Transmission efficiency & 0.96 & assumption \\
\hline
\end{tabular}

The powertrain configuration is explored in terms of motor type and gear ratio. The motor types evaluated included IM and PMSM, which are modeled using motor efficiency maps. To enable a fair comparison, the efficiency maps were generated by a validated motor simulation tool using the same nominal voltage, maximal and nominal rotational speed, cooling type, number of pole pairs and nominal power, as listed in Table 3 [46]. The values are based on the motor used by the reference vehicle [47]. The simulation model used a squirrel-cage rotor for the IM and a rotor with internal permanent magnets for the PMSM.

Table 3. Motor parameters.

\begin{tabular}{ll}
\hline Parameter & Value \\
\hline Nominal voltage & $540 \mathrm{~V}$ \\
Max. rotational speed & $7500 \mathrm{U} / \mathrm{min}$ \\
Nominal rotational speed & $3500 \mathrm{U} / \mathrm{min}$ \\
Type of cooling & liquid \\
Number of pole pairs & 4 \\
Nominal power & $90 \mathrm{~kW}$ \\
\hline
\end{tabular}

Data from the Singapore Land Transport Authority were used to derive the route infrastructure parameters. A turning radius of $12 \mathrm{~m}$, which corresponds to the minimum corner radius specified by Singapore infrastructure guidelines, was used for all turns [48]. Combined with the suggested maximum lateral acceleration of $0.05 \mathrm{~g}$ [48], this results in a maximum cornering speed of $8.7 \mathrm{~km} / \mathrm{h}$. The signal phase durations of the traffic lights along the routes were provided by the Singapore Land Transport Authority. The start of each green phase was aligned with the data from the measured bus routes as follows. At the traffic lights where the bus had to stop, the time at which it resumed driving was used for the start of the green phase. At the traffic lights where the measured bus did not stop, it was assumed that it passed halfway through a green phase.

\section{Results}

\subsection{Speed Profiles}

Figure 3 illustrates optimal speed profiles for the CEEDB with a PMSM and an IM with their optimal gear ratio with and without the comfort factor (e.g., PMSM-Comfort indicates the CEEDB PMSM with controlled comfort) on a stretch of Route 91 along with the measured driving cycle of the UCB operating on that route. The bus stops and traffic lights are indicated in the figure with vertical lines. Without the comfort factor, the figure shows similar speed profiles for PMSM and IM, with primarily three phases of movement, including acceleration, coasting with no applied motor torque and deceleration. A P\&G strategy can be seen. With the applied comfort factor, the speed profiles are smoother, but the three phases of movement can still be identified. 


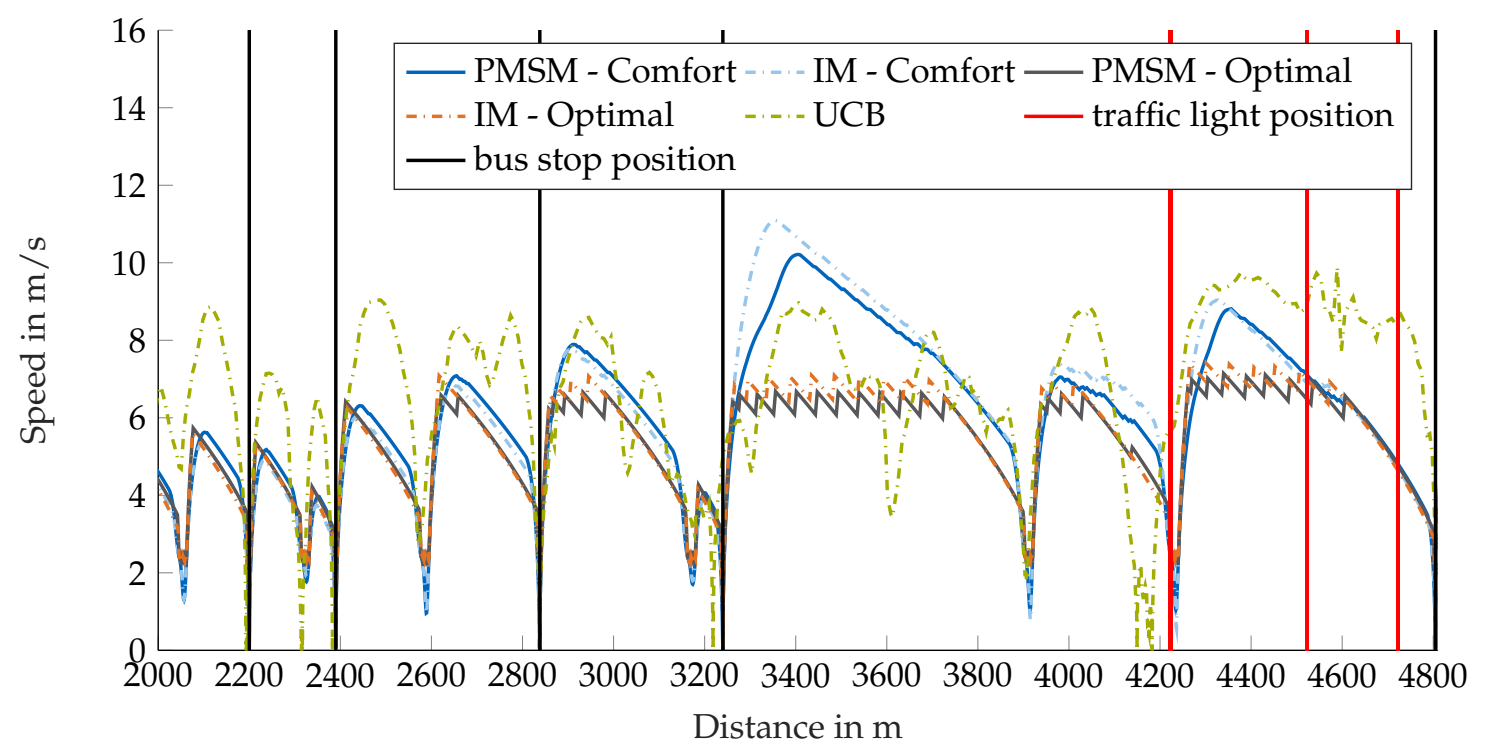

Figure 3. Extracted optimized speed profiles for best PMSM and IM configuration on Route 91.

The UCB has to stop more often as traffic lights, right turns with oncoming traffic or traffic congestion may force it to stop. These stop events are avoided by the CEEDB and, therefore, the CEEDB drives slower but continuously, only stopping at bus stops. Queuing vehicles explain the shift between the actual stop position of the UCB and traffic light positions. The small shift between bus stops and the stop position of the UCB can be explained by measuring errors. The respective load points within the efficiency map for the speed profiles with the comfort factor are shown in Figure 4.

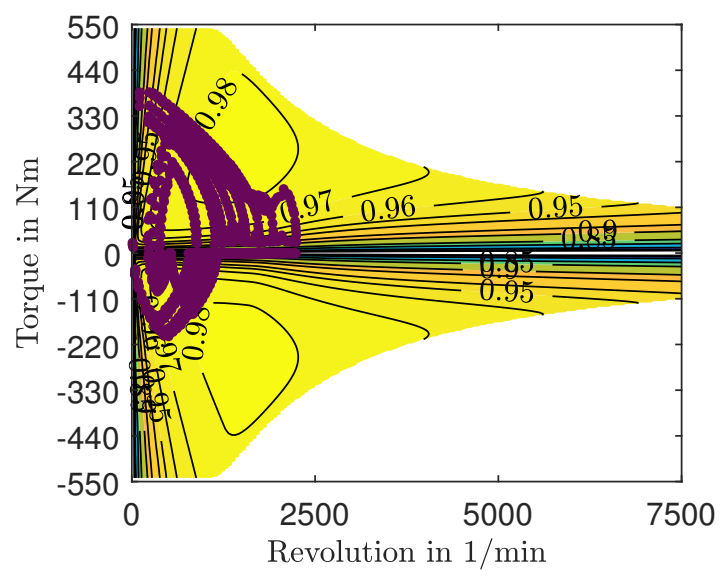

(a)

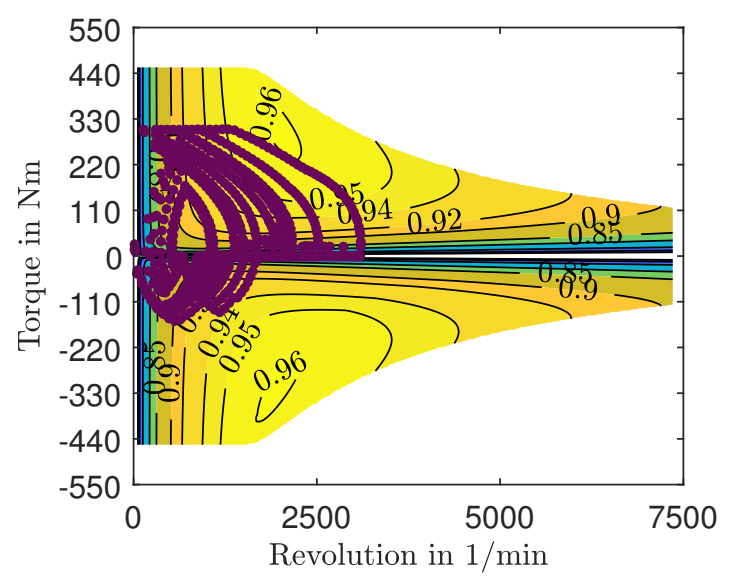

(b)

Figure 4. Load points of optimized speed profiles (CEEDB) with comfort factor of (a) PMSM and (b) IM.

\subsection{Powertrain Optimization Analyses}

As the speed profiles without the comfort factor seem uncomfortable due to the occurring $P \& G$, further discussion focuses on the speed profiles with the comfort factor. Figures 5 and 6 show the optimal gear ratio for each motor type along with the change in energy consumption for different gear ratios for the CEEDB with the comfort factor and the UCB operating on Route 91 and Route 185, respectively. 


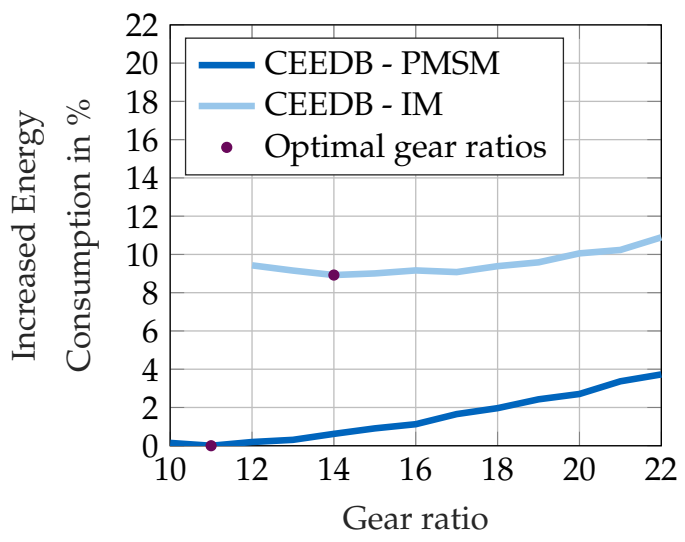

(a)

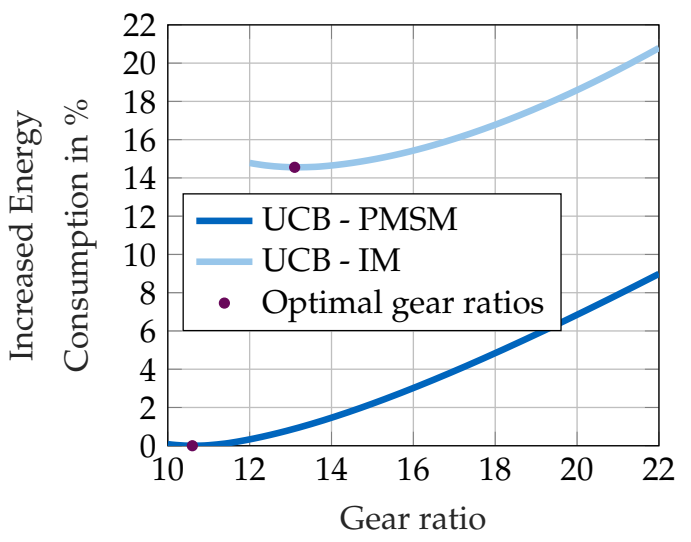

(b)

Figure 5. Comparison of relative energy consumption for different powertrains for (a) the connected energy-efficient driven bus (CEEDB) with comfort factor and (b) the unconnected bus (UCB) on Route 91.

As can be seen from the figures, gear ratios range from 10 to 22 for the PMSM and 12 to 22 for the IM, as they correspond to a minimal gradeability of $12 \%$ and a minimal top speed of $60 \mathrm{~km} / \mathrm{h}$ for the reference vehicle. For both routes, the PMSM performed best for the CEEDB and UCB. The IM required more energy than the PMSM for all cases. For the CEEDB, the optimal gear ratios are higher compared to the UCB for the IM but similar for the PMSM. As the region of best efficiency for the IM is at higher revolutions, the optimal gear ratio was higher compared to that of the PMSM, which moves the load points to higher motor revolutions, as can be seen in Figure 4. The sensitivity of the energy consumption over the gear ratio is lower for the CEEDB. On Route 91, for the CEEDB with the comfort factor, the optimal gear ratio may result in energy savings of up to $3.7 \%$ and $1.8 \%$ for the PMSM and IM, respectively, while for the UCB, energy savings of up to $9 \%$ and $6.2 \%$ can be achieved for the PMSM and IM, respectively. On Route 185, for the CEEDB with the comfort factor, optimal gear ratio may result in energy savings of up to $4.2 \%$ and $2.9 \%$ for the PMSM and IM, respectively, while for the UCB, energy savings of up to $10.1 \%$ and $9.9 \%$ can be achieved for the PMSM and IM, respectively.

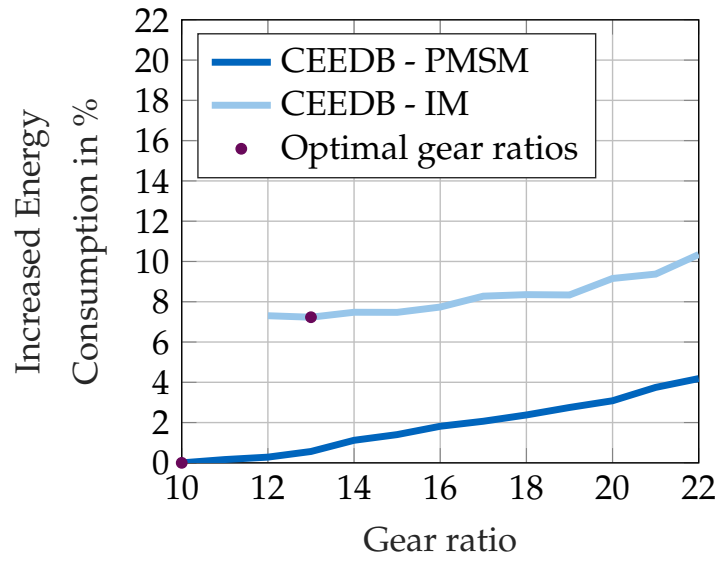

(a)

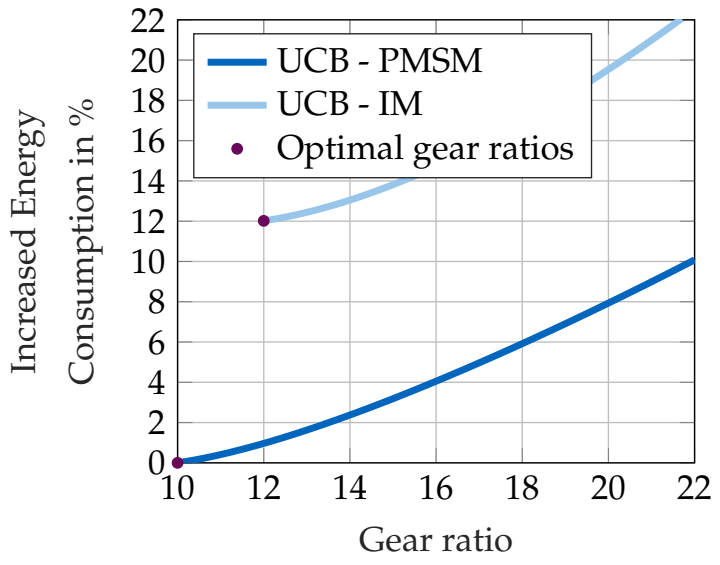

(b)

Figure 6. Comparison of relative energy consumption for different powertrains for (a) the CEEDB with the comfort factor and (b) the UCB on Route 185. 
Figure 7 illustrates the lowest achieved energy consumption of each motor for the CEEDB with and without the comfort factor and UCB. As expected, the energy consumption for the optimal controlled vehicle with a dedicated lane and V2I communication is significantly lower than the UCB for all motors and routes. Between the CEEDB and the UCB, savings of up to $27 \%$ can be achieved. With the comfort factor (indicated with C), the energy consumption is $6.8-10.8 \%$ and $6.5-8.9 \%$ higher compared to the CEEDB without the comfort factor for PMSM and IM, respectively.

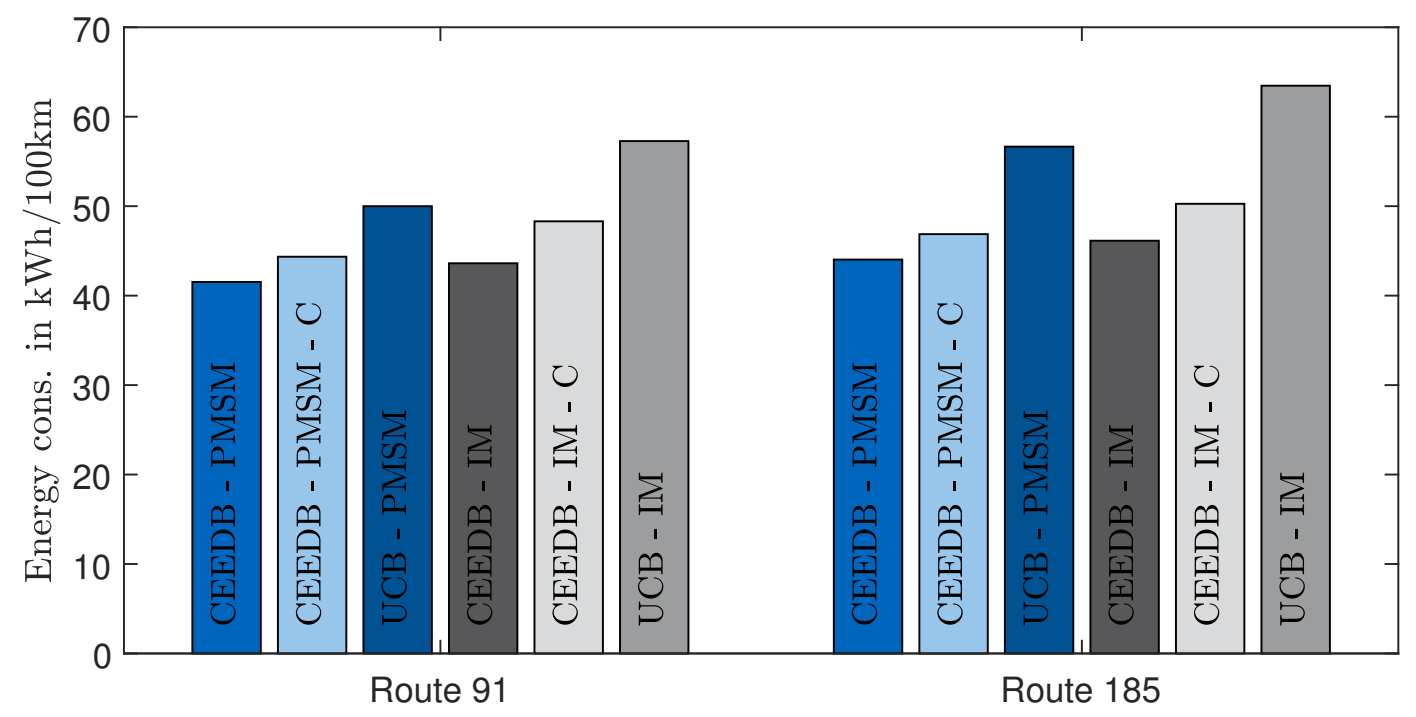

Figure 7. Required energy consumption of the best powertrain configuration for the CEEDB and UCB.

The share of gear-ratio-specific operation on energy consumption is explored by evaluating one optimized speed profile for different gear ratios for the PMSM and IM. The speed profile of the smallest gear ratio was chosen for the fixed speed profile for each motor. Figure $8 \mathrm{a}, \mathrm{b}$ show the energy consumption relative to the best configuration for the PMSM and IM, with the fixed and gear-ratio-specific optimized speed profiles for Route 91 with and without the comfort factor, respectively. The difference in the energy consumption can be explained by the gear-ratio-specific operation. It can be seen from the figure that for the CEEDB with IM, the effect of gear-ratio-specific operation is noticeable only at high gear ratios. However, with the PMSM, the effect of gear-ratio-specific operation becomes more pronounced, resulting in savings of up to $1 \%$ based on the minimal archived energy consumption. For the CEEDB with PMSM, it can be seen that the impact of gear ratio on energy consumption decreases even more if comfort is neglected. 


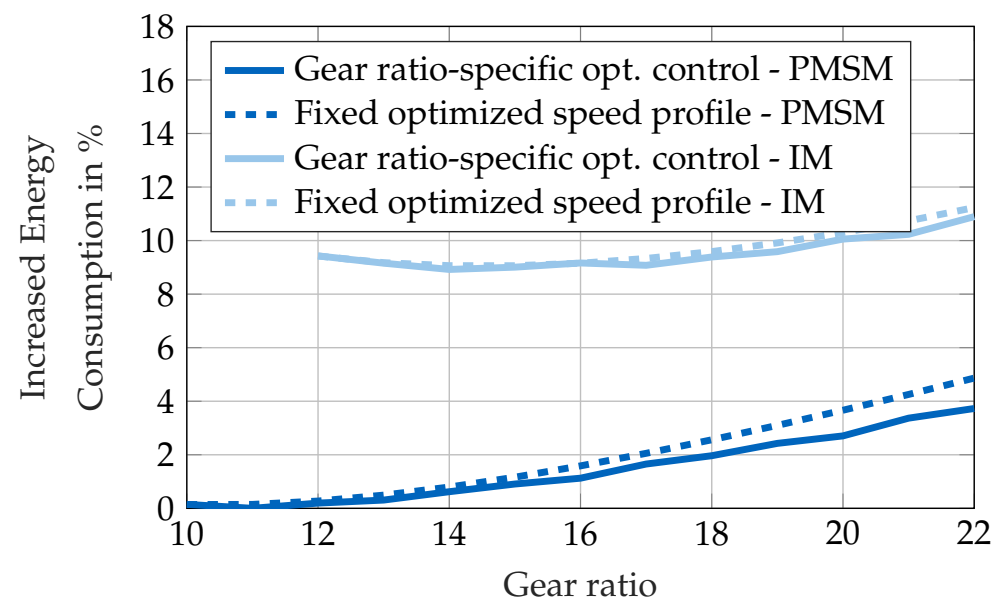

(a)

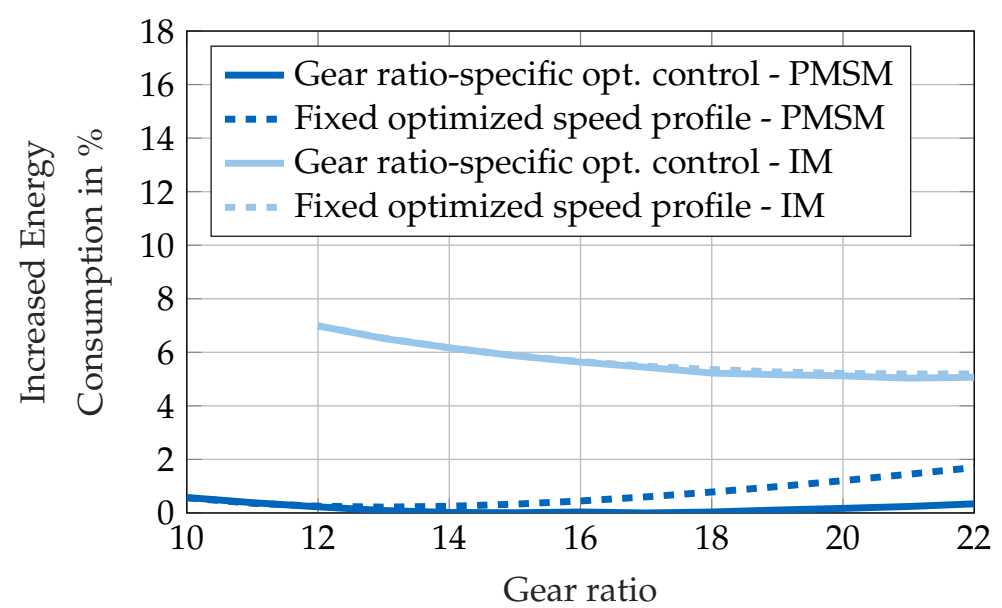

(b)

Figure 8. Comparison of relative energy consumption for gear ratio-specific optimized speed profiles and fixed optimized speed profiles (a) with the comfort factor and (b) without the comfort factor for Route 91.

\section{Discussion}

\subsection{Sensitivity Analysis}

A sensitivity analysis was conducted for the CEEDB without the comfort factor, varying the time and acceleration limit by $20 \%$. The simulations were conducted for the first four bus stops of Route 91 without traffic lights to reduce computation time. As a reference, the maximum time was set to $224.1 \mathrm{~s}$, which corresponds to an average speed of $20 \mathrm{~km} / \mathrm{h}$, and the reference acceleration was set to $1 \mathrm{~m} / \mathrm{s}^{2}$.

Figure $9 \mathrm{a}-\mathrm{c}$ show the optimal gear ratio for each motor type along with the change in energy consumption for different gear ratios for the varying maximal arrival times.

The optimal gear ratio for each motor type along with the change in energy consumption for different gear ratios for the different acceleration limits of $0.8,1$ and $1.2 \mathrm{~m} / \mathrm{s}^{2}$ can be seen in $a, b$ and $c$ of Figure 10, respectively. 


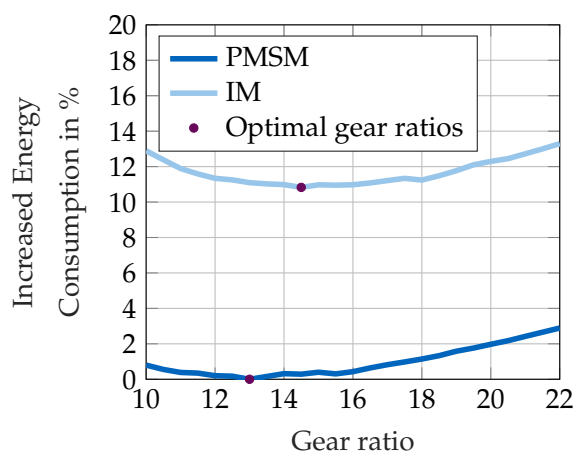

(a)

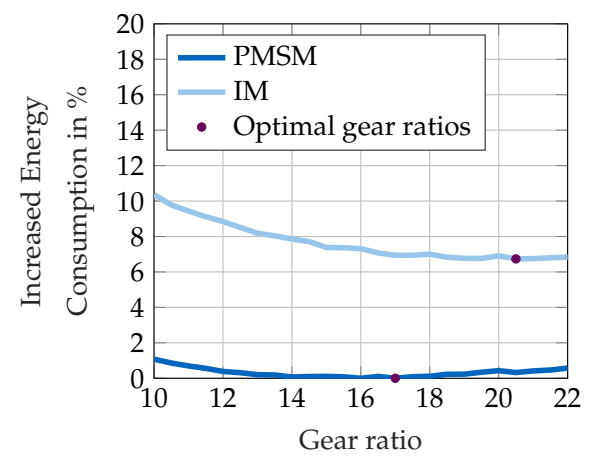

(b)

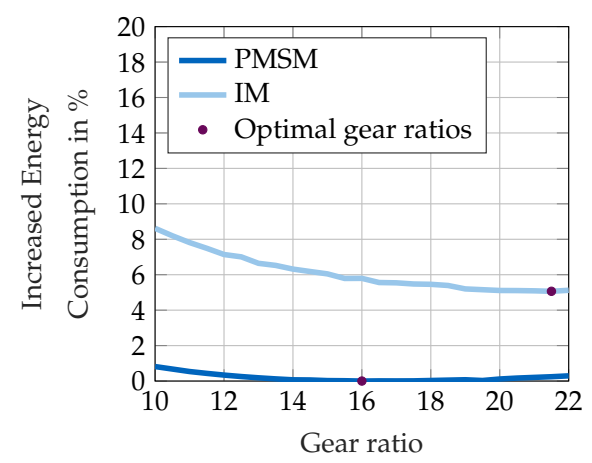

(c)

Figure 9. Comparison of relative energy consumption for different powertrains for a maximal arrival time of (a) $-20 \%$ (b) reference (c) $+20 \%$.

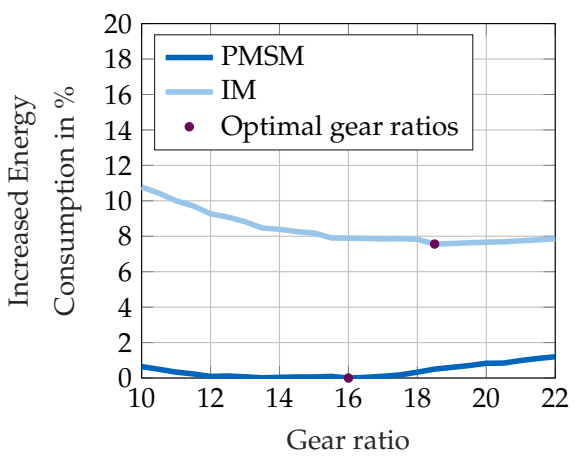

(a)

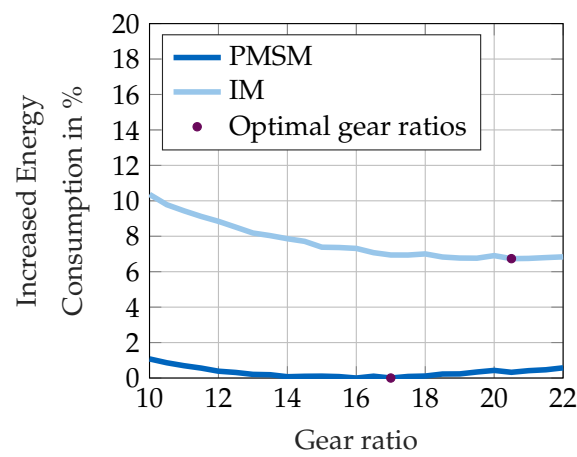

(b)

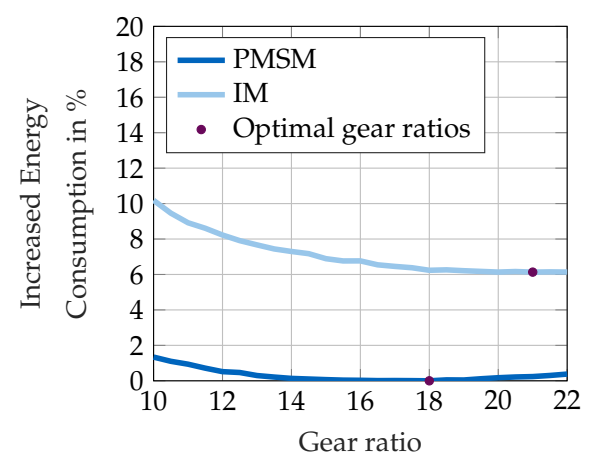

(c)

Figure 10. Comparison of relative of energy consumption for different powertrains for a maximal acceleration of (a) $-20 \%(\mathbf{b})$ reference $(\mathbf{c})+20 \%$. 
The relative difference between PMSM and IM decreases with released boundary conditions. This can be explained by the efficiency maps. The PMSM has high efficiency over a broad range, while the IM's efficiency varies significantly with torque and RPM. Therefore, with the released boundary conditions, the IM has more potential to shift the load points to a higher efficiency area. Thus, the life cycle costs of the IM become more competitive, as the acquisition cost of the IM is lower than that of a PMSM.

\subsection{Ride Comfort}

The literature has shown the effect of a P\&G strategy to achieve maximal efficiency for combustion engines [5,11]. This work has shown, similar to [7], that $P \& G$ maximizes efficiency for electric motors as well, which can be explained by load point shifting. As load points at low torques have low efficiencies, it may be more efficient with the implemented model to repeatedly accelerate in short increments with a high torque, followed by some coasting, than to drive at a constant speed. However, this results in an uncomfortable speed profile. Therefore, a comfort factor is required to enable passenger comfort.

\subsection{Effect of Gear Ratios on Energy Consumption}

For optimal speed profiles, the impact of gear ratio on energy consumption decreases compared to the UCB, as can be seen from Figures 5 and 6 . The reduced change in energy consumption over gear ratios can be explained in two possible ways. One is that longer coasting but shorter acceleration and recuperation periods may reduce the effect of gear ratio. The energy consumption of the coasting phases is independent of the gear ratio in the implemented model. The short acceleration and recuperation phases are driven with high torque and hence result in load points at higher efficiency areas with small gradients for all gear ratios. Therefore, the gear ratios may not further improve the energy consumption of the optimized speed profiles with predominantly coasting phase and acceleration and recuperation phases that are already in high efficiency areas. Another explanation is that the effect of gear ratio on energy consumption may subside because of the gear-ratio-specific operation, as the speed profiles are optimized for each powertrain configuration.

For the CEEDB with PMSM, both effects are significant, as can be seen from Figure 8. Thus, the great share of coasting and the gear-ratio-specific operation reduce the sensitivity. However, for the CEEDB with IM, the effect of coasting is dominant, as can be seen in Figure 8. Due to the low acceleration limit combined with the slow speed and the desired high motor speed for best efficiency, the acceleration profiles for the considered gear ratios look almost identical. Thus, the effect of gear-ratio-specific control is smaller for the IM in this scenario.

\subsection{Limitations}

This study compared different powertrain configurations for vehicles operating under energy-efficient driving, which may apply to connected vehicles with speed advisory systems as well as to automated/autonomous vehicles. In the former, a human driver controls the vehicle and the optimal speed profile is only an advisory which may or may not be followed. Accordingly, the extent of the described effects on the powertrain design due to energy-efficient driving depend on the adoption rate of the human driver. The automation of vehicles takes the human out of the loop. Thus, autonomous vehicles are seen as enablers of energy-efficient driving. However, they require high maturity of autonomous driving functions. In this work, we assumed the vehicle parameters of a state-of-the art electric production bus. This allows an isolated examination of the energy-efficient operation's impact on the powertrain design. However, today's concepts of autonomous buses differ in design and their maximum speed is low $[49,50]$. Thus, the actual energy consumption for current autonomous buses may differ from our results.

As Singapore has no dedicated lanes for buses, it was not possible to obtain measured driving cycles and the necessary geo-data for a bus with a dedicated infrastructure to derive the benchmark for the optimization results. Thus, the measurements were conducted at off-peak hours with 
low traffic to obtain speed profiles that were close to those of a bus operating in a dedicated lane. Furthermore, the measured speed profiles were filtered to remove unrealistic accelerations. This may limit the accuracy of the absolute energy consumption of the UCB. Without the comfort factor, the results are globally optimal within the discretization of the model; however, inclusion of jerk requires a new state, which would increase calculation time. Therefore, the new state was not introduced and the speed profiles with the comfort factor are not a global minimum per se.

Only one motor of two different kinds was analyzed. The IM with its significant change in efficiency over torque and RPM becomes more competitive with the introduction of energy-efficient driving and released boundary conditions. Based on the design parameters, the efficiency map of different PMSM and IMs can focus on maximal efficiency or high overall efficiency. Subsequently, further research with multiple PMSMs and IMs is required to derive trends in motor design for vehicles under energy-efficient driving.

The analysis in this study is limited to single speed transmission systems. Previous studies have shown the potential reduction in the energy consumption of multi-gear or continuously variable transmissions for fixed driving cycles [23]. Further research is required to assess this potential for CEEDBs.

The achieved energy savings in this study were higher compared to those of the reviewed literature [8]. This may be explained by the fact that the energy savings in this study are achieved due to the combination of optimal control and V2I communication.

Finally, the study was limited to buses that drive in a dedicated lane and have traffic light information available. Although the work did not focus on the implementation of the driving strategies in real time, an implementation could be realized by communicating the desired speed to the vehicles based on its location, as shown in [51]. To extend the validity of the results, an analysis of a bus within dynamically changing boundary conditions, like mixed traffic, should be conducted. However, this would introduce additional constraints to the system, which would require advanced control strategies.

\section{Conclusions}

This study demonstrated optimal powertrain configurations for a connected, energy-efficient driven bus and a human-driven unconnected bus. The impact of powertrain configuration for the connected, energy-efficient driven bus was further evaluated for the cases of powertrain-specific optimal speed, non-powertrain-specific optimal speed and with and without consideration of ride comfort. It was shown that the connectivity and speed optimization may reduce the energy consumption of a bus by up to $27 \%$.

The PMSM has lower energy consumption compared to the IM for all considered cases. However, with released boundary conditions, the difference in energy consumption decreases between PMSM and IM, making the cheaper IM more competitive.

The optimal gear ratio for PMSM is smaller than that of the IM. This is mainly due to the IM having higher efficiencies at higher speeds and therefore requiring higher gear ratios to shift the operating points to higher motor revolutions. However, the optimal gear ratio does not change significantly for the connected bus under energy-efficient driving when the comfort factor is considered compared to that of the human-driven unconnected bus.

The connected bus under optimal speed control predominantly operates at coasting, which is independent of the powertrain, and the remaining operating phases, acceleration and recuperation, already correspond to the high motor efficiencies for all regarded powertrain configurations. Hence, the change in energy consumption over different gear ratios subsides for the connected energy-efficient driven bus. Furthermore, due to the powertrain-specific optimization of the speed profiles, the change in energy consumption over different gear ratios subsides even more compared to the human-driven unconnected bus. The reduced sensitivities show that intelligent driving may help powertrain designers to achieve a good compromise between drivability and energy consumption. 
Author Contributions: A.K. is the initiator of the research topic, developed the dynamic programming algorithm and revised the paper to its final status. O.T. defined the use cases for the analysis, drafted the structure of the paper and was intensively involved in the paper revisions. S.K. generated the motor efficiency maps and contributed to the discussion on different motor types. A.O. is the principal investigator of the research project and gave constructive comments on the paper. M.L. made an essential contribution to the conception of the research project. He revised the paper critically for important intellectual content. M.L. gave final approval of the version to be published and agrees to all aspects of the work. As a guarantor, he accepts responsibility for the overall integrity of the paper. Conceptualization, A.K. and O.T.; methodology, A.K. and O.T; software, A.K. and O.T.; validation, A.K., O.T. and S.K.; formal analysis, A.K. and O.T.; investigation, A.K. and O.T.; data curation, O.T.; writing-original draft preparation, A.K and O.T.; writing-review and editing, A.K., O.T. and A.O.; visualization, A.K. and O.T.; supervision, A.O. and M.L.; All authors have read and agreed to the published version of the manuscript.

Funding: This work was financially supported by the Singapore National Research Foundation under its Campus for Research Excellence And Technological Enterprise (CREATE) programme.

Conflicts of Interest: The authors declare no conflict of interest.

\section{Abbreviations}

The following abbreviations are used in this manuscript:

$\begin{array}{ll}\text { BEV } & \text { Battery electric vehicle } \\ \text { CEEDB } & \text { Connected energy-efficient driven bus } \\ \text { DP } & \text { Dynamic programming } \\ \text { IM } & \text { Induction motor } \\ \text { NEDC } & \text { New European Driving Cycle } \\ \text { P\&G } & \text { Pulse and glide } \\ \text { PMP } & \text { Pontryagin's Maximum Principle } \\ \text { PMSM } & \text { Permanent magnet synchronous motor } \\ \text { UCB } & \text { Unconnected bus } \\ \text { V2I } & \text { Vehicle to infrastructure }\end{array}$

\section{Appendix A}

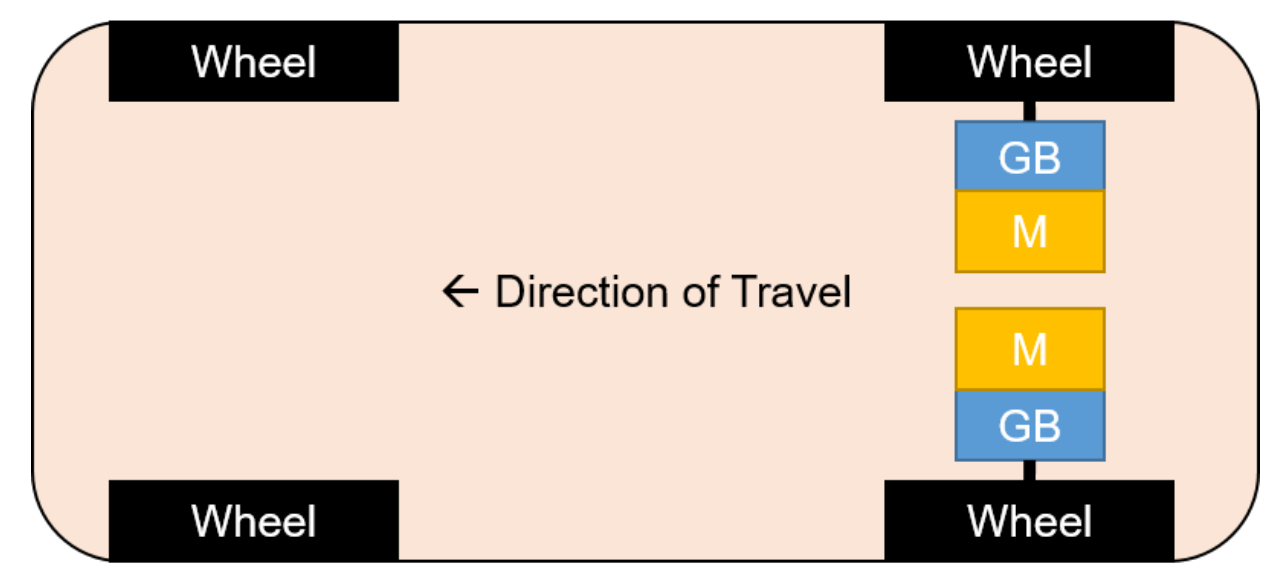

Figure A1. Overview of vehicle's powertrain structure with its gearbox (GB) and motor (M).

\section{References}

1. Energy Market Authority. Singapore Energy Statistics 2018. 2018. Available online: https: / / www.ema.gov.sg/cmsmedia/Publications_and_Statistics/Publications/SES18/Publication_Singa pore_Energy_Statistics_2018.pdf (accessed on 11 June 2019).

2. NCCS. Land Transport Carbon Emissions by Vehicle Mode (2005). 2019. Available online: https:/ /www.nc cs.gov.sg/climate-change-and-singapore/reducing-emissions/transport (accessed on 24 May 2019). 
3. Authority, L.T. Annual Vehicle Statistics 2018: Motor Vehicle Population By Vehicle Type. 2019. Available online: https: / / www.lta.gov.sg/content/dam/ltaweb/corp/PublicationsResearch/files/FactsandFigures/MVP 01-1_MVP_by_type.pdf (accessed on 24 June 2019).

4. Sciarretta, A. Energy-Efficient Driving of Road Vehicles: Toward a Cooperative, Connected, and Automated Mobility; Springer International Publishing: Berlin/Heidelberg, Germany, 2019.

5. Han, J.; Vahidi, A.; Sciarretta, A. Fundamentals of energy efficient driving for combustion engine and electric vehicles: An optimal control perspective. Automatica 2019, 103, 558-572. [CrossRef]

6. Eo, J.S.; Kim, S.J.; Oh, J.; Chung, Y.K.; Chang, Y.J. A Development of Fuel Saving Driving Technique for Parallel HEV; SAE Technical Paper Series; SAE International 400 Commonwealth Drive: Warrendale, PA, USA, 2018. [CrossRef]

7. So, K.M.; Gruber, P.; Tavernini, D.; Karci, A.E.H.; Sorniotti, A.; Motaln, T. On the Optimal Speed Profile for Electric Vehicles. IEEE Access 2020, 8, 78504-78518, [CrossRef]

8. Lajunen, A. Energy-optimal velocity profiles for electric city buses. In Proceedings of the 2013 IEEE International Conference on Automation Science and Engineering, Madison, WI, USA, 29-30 July 2013; pp. 886-891. [CrossRef]

9. Kelouwani, S.; Agbossou, K.; Dubé, Y.; Boulon, L. Energetic optimization of the driving speed based on geographic information system data. In Proceedings of the 2012 IEEE Vehicular Technology Conference (VTC Fall), Quebec City, QC, Canada, 3-6 September 2012; pp. 1-5.

10. Mensing, F.; Trigui, R.; Bideaux, E. Vehicle trajectory optimization for application in ECO-driving. In Proceedings of the 2011 IEEE Vehicle Power and Propulsion Conference, Chicago, IL, USA, 6-9 September 2011; pp. 1-6.

11. Luu, H.T.; Nouvelière, L.; Mammar, S. Dynamic programming for fuel consumption optimization on light vehicle. IFAC Proc. Vol. 2010, 43, 372-377. [CrossRef]

12. Nouveliere, L.; Braci, M.; Menhour, L.; Luu, H.; Mammar, S. Fuel consumption optimization for a city bus. In Proceedings of the UKACC Control Conference, Manchester, UK, 1-4 September 2008; pp. 1-6.

13. Ilgin, Guler, S.; Menendez, M.; Meier, L. Using connected vehicle technology to improve the efficiency of intersections. Transp. Res. Part C Emerg. Technol. 2014, 46, 121-131. [CrossRef]

14. Katsaros, K.; Kernchen, R.; Dianati, M.; Rieck, D. Performance study of a Green Light Optimized Speed Advisory (GLOSA) application using an integrated cooperative ITS simulation platform. In Proceedings of the 2011 7th International Wireless Communications and Mobile Computing Conference, Istanbul, Turkey, 4-8 July 2011; pp. 918-923. [CrossRef]

15. Amir, G.; Xiaopeng, L.; Zhitong, H.; Xiaobo, Q. A Joint Trajectory and Signal Optimization Model for Connected Automated Vehicles. In Proceedings of the TRB Annual Meeting, Washington, DC, USA, 10-11 July 2019.

16. Teichert, O.; Koch, A.; Ongel, A. Comparison of Eco-Driving Strategies for Different Traffic-Management Measures. In Proceedings of the 2020 IEEE Intelligent Transportation Systems Conference (ITSC), Rhodes, Greece, 20-23 September 2020; pp. 1867-1873.

17. Wang, Q.; Santini, D.L. Magnitude and Value of Electric Vehicle Emissions Reductions for Six Driving Cycles in Four US Cities with Varying Air Quality Problems; Technical Report; Argonne National Lab.: Lemont, IL, USA, 1992.

18. Thomas, C. Fuel cell and battery electric vehicles compared. Int. J. Hydrog. Energy 2009, 34, 6005-6020. [CrossRef]

19. Egbue, O.; Long, S. Barriers to widespread adoption of electric vehicles: An analysis of consumer attitudes and perceptions. Energy Policy 2012, 48, 717-729. [CrossRef]

20. Angerer, C.; Krapf, S.; Buß, A.; Lienkamp, M. Holistic Modeling and Optimization of Electric Vehicle Powertrains Considering Longitudinal Performance, Vehicle Dynamics, Costs and Energy Consumption. In Proceedings of the ASME 2018 International Design Engineering Technical Conferences and Computers and Information in Engineering Conference, American Society of Mechanical Engineers, Quebec City, QC, Canada, 26-29 August 2018; p. V003T01A024.

21. Ren, Q.; Crolla, D.; Morris, A. Effect of transmission design on Electric Vehicle (EV) performance. In Proceedings of the 5th IEEE Vehicle Power and Propulsion Conference (VPPC'09), Dearborn, MI, USA, 7-11 September 2009; pp. 1260-1265. [CrossRef] 
22. Hofman, I.; Sergeant, P.; Van den Bossche, A. Drivetrain design for an ultra light electric vehicle with high efficiency. In Proceedings of the 2013 World Electric Vehicle Symposium and Exhibition (EVS27), Barcelona, Spain, 17-20 November 2013; pp. 1-6. [CrossRef]

23. Bottiglione, F.; de Pinto, S.; Mantriota, G.; Sorniotti, A. Energy Consumption of a Battery Electric Vehicle with Infinitely Variable Transmission. Energies 2014, 7, 8317-8337. [CrossRef]

24. Zeraoulia, M.; Benbouzid, M.E.H.; Diallo, D. Electric Motor Drive Selection Issues for HEV Propulsion Systems: A Comparative Study. IEEE Trans. Veh. Technol. 2006, 55, 1756-1764. [CrossRef]

25. De Santiago, J.; Bernhoff, H.; Ekergård, B.; Eriksson, S.; Ferhatovic, S.; Waters, R.; Leijon, M. Electrical Motor Drivelines in Commercial All-Electric Vehicles: A Review. IEEE Trans. Veh. Technol. 2012, 61, 475-484. [CrossRef]

26. Xue, X.D.; Cheng, K.W.E.; Cheung, N.C. Selection of Electric Motor Drives for Electric Vehicles. In Proceedings of the 2008 Australasian Universities Power Engineering Conference, Sydney, Australia, 14-17 December 2008.

27. Lukic, S.M.; Emado, A. Modeling of electric machines for automotive applications using efficiency maps. In Proceedings of the Electrical Insulation Conference and Electrical Manufacturing and Coil Winding Technology Conference (Cat. No.03CH37480), Indianapolis, Indiana, 23-25 September 2003; pp. 543-550. [CrossRef]

28. Yang, Z.; Shang, F.; Brown, I.P.; Krishnamurthy, M. Comparative Study of Interior Permanent Magnet, Induction, and Switched Reluctance Motor Drives for EV and HEV Applications. IEEE Trans. Transp. Electrif. 2015, 1, 245-254. [CrossRef]

29. Goss, J.; Popescu, M.; Staton, D. A comparison of an interior permanent magnet and copper rotor induction motor in a hybrid electric vehicle application. In Proceedings of the 2013 International Electric Machines \& Drives Conference, Chicago, IL, USA, 12-15 May 2013; pp. 220-225. [CrossRef]

30. Pellegrino, G.; Vagati, A.; Boazzo, B.; Guglielmi, P. Comparison of Induction and PM Synchronous Motor Drives for EV Application Including Design Examples. IEEE Trans. Ind. Appl. 2012, 48, 2322-2332. [CrossRef]

31. Wang, B.; Hung, D.L.S.; Zhong, J.; Teh, K.Y. Energy Consumption Analysis of Different Bev Powertrain Topologies by Design Optimization. Int. J. Automot. Technol. 2018, 19, 907-914, [CrossRef]

32. Tate, L.; Hochgreb, S.; Hall, J.; Bassett, M. Energy Efficiency of Autonomous Car Powertrain; SAE Technical Paper Series; SAE International 400 Commonwealth Drive: Warrendale, PA, USA, 2018. [CrossRef]

33. Anselma, P.G.; Belingardi, G. Enhancing Energy Saving Opportunities through Rightsizing of a Battery Electric Vehicle Powertrain for Optimal Cooperative Driving. SAE Int. J. Connect. Autom. Veh. 2020, 3. [CrossRef]

34. Ullekh Raghunatha Gambhira. Powertrain Optimization of an Autonomous Electric Vehicle. Master's Thesis, The Ohio State University, Columbus, OH, USA, 2018.

35. Bertsekas, D.P. Dynamic Programming and Optimal Control, 4th ed.; Athena Scientific: Belmont, MA, USA, 2017.

36. Guzzella, L.; Sciarretta, A. Vehicle Propulsion Systems: Introduction to Modeling and Optimization, 3rd ed.; Springer: Berlin/Heidelberg, Germany, 2013. [CrossRef]

37. Naunheimer, H.; Bertsche, B.; Lechner, G. Fahrzeuggetriebe. In Grundlagen, Auswahl, Auslegung und Konstruktion./Harald Naunheimer, Bernd Bertsche, Gisbert Lechnerv; Springer: Berlin/Heidelberg, Germany, 2007.

38. Sundstrom, O.; Guzzella, L. A generic dynamic programming Matlab function. In Proceedings of the 2009 IEEE Control Applications, (CCA) Intelligent Control, (ISIC), Capri, Italy, 9-11 June 2009; pp. 1625-1630. [CrossRef]

39. Marler, R.T.; Arora, J.S. The weighted sum method for multi-objective optimization: New insights. Struct. Multidiscip. Optim. 2010, 41, 853-862. [CrossRef]

40. Bae, S.; Kim, Y.; Guanetti, J.; Borrelli, F.; Moura, S. Design and implementation of ecological adaptive cruise control for autonomous driving with communication to traffic lights. In Proceedings of the 2019 American Control Conference (ACC), Philadelphia, PA, USA, 10-12 July 2019; pp. 4628-4634.

41. Kamal, M.A.S.; Mukai, M.; Murata, J.; Kawabe, T. Ecological driving based on preceding vehicle prediction using MPC. IFAC Proc. Vol. 2011, 44, 3843-3848. [CrossRef]

42. Wittmann, M.; Lohrer, J.; Betz, J.; Jäger, B.; Kugler, M.; Klöppel, M.; Waclaw, A.; Hann, M.; Lienkamp, M. A holistic framework for acquisition, processing and evaluation of vehicle fleet test data. In Proceedings of the 2017 IEEE 20th International Conference on Intelligent Transportation Systems (ITSC), Yokohama, Japan, 16-19 October 2017; pp. 1-7. 
43. LTA Singapore. Data Mall. Available online: https://www.mytransport.sg/content/mytransport/home/da taMall.html (accessed on 8 May 2019).

44. BYD. 12M BATTERY-ELECTRIC BUS—Specifications. Technical Data Sheet; 2019. Available online: http: / / bydeurope.com/vehicles/ebus/types/12.php (accessed on 27 May 2019).

45. Kivekas, K.; Lajunen, A.; Baldi, F.; Vepsalainen, J.; Tammi, K. Reducing the Energy Consumption of Electric Buses With Design Choices and Predictive Driving. IEEE Trans. Veh. Technol. 2019, 68, 11409-11419. [CrossRef]

46. Kalt, S.; Erhard, J.; Danquah, B.; Lienkamp, M. Electric Machine Design Tool for Permanent Magnet Synchronous Machines. In Proceedings of the 2019 Fourteenth International Conference on Ecological Vehicles and Renewable Energies (EVER), Monte-Carlo, Monaco, 8-10 May 2019.

47. BYD. 12M BATTERY-ELECTRIC BUS-UNIQUE INNOVATIVE DESIGN. Technical Data Sheet. 2019. Available online: http:/ / bydeurope.com/innovations/technology/index.php\#motor (accessed on 8 May 2019).

48. LTA Singapore. Civil Design Criteria For Road And Rail Transit Systems. E/GD/09/106/A2. 2019. Available online: https://www.lta.gov.sg/content/dam/ltagov/industry_innovations/industry_matter s/development_construction_resources/civil_standards/pdf/EGD09106A2_Overall.pdf (accessed on 5 December 2020).

49. Frank Mertens. Into the Future with the People Mover. 2018. Available online: https://www.zf.com/mobil e/en/stories_7809.html (accessed on 24 November 2020).

50. Local Motors. Meet-Olli. 2020. Available online: https://localmotors.com/meet-olli/ (accessed on 24 November 2020).

51. Lin, X.; Görges, D.; Liu, S. Eco-driving assistance system for electric vehicles based on speed profile optimization. In Proceedings of the 2014 IEEE Conference on Control Applications (CCA), Nice, France, 8-10 October 2014; pp. 629-634.

Publisher's Note: MDPI stays neutral with regard to jurisdictional claims in published maps and institutional affiliations.

(C) 2020 by the authors. Licensee MDPI, Basel, Switzerland. This article is an open access article distributed under the terms and conditions of the Creative Commons Attribution (CC BY) license (http:/ / creativecommons.org/licenses/by/4.0/). 